in vitro with IL-3 for 6 or 24 hours. WB RNASeq analysis was also undertaken in $n=31$ SLE donors from the Monash Lupus Clinic and $\mathrm{n}=28$ HDs.

Results Serum IL-3 levels correlated with serum IFN $\alpha$ $(\mathrm{r}=0.612,95 \%$ CI $0.455-0.733, \mathrm{p}<0.001)$. IL-3 stimulation in vitro altered 794 genes $(-1 \geq \operatorname{logFC} \geq 1$, FDR $<0.05)$. Thirtyfive of these genes overlapped with differentially expressed genes between SLE and HD. These 35 genes were expressed in 28/31 SLE donors, revealing the presence of an 'IL-3 gene signature'. There was strong correlation between the IL-3 signature and an IFN signature determined by heirarchical clustering of the five hundred most variable genes in SLE donors $(r=0.939$, 95\% CI 0.898-0.964, $\mathrm{p}<0.0001)$.

Conclusions We have previously reported a novel anti-IL-3R $\alpha$ $\mathrm{mAb}$ (CSL362/JNJ-473), which depletes pDCs and reduces IFN $\alpha$ production, as well as neutralising IL-3 signalling (Oon S, JCI Insight, 2016). An association between IL-3 and IFN $\alpha$ was found in this study, raising the possibility that CSL362 may be especially useful for lupus patients with a dual IL-3/ IFN gene signature.

\section{URINARY VCAM 1 AS A DISEASE ACTIVITY INDICATOR IN LUPUS NEPHRITIS}

'S Padiyar*, 1J Mathew, ${ }^{2}$ TS Vijayakumar. 'Christian Medical College, RHEUMATOLOGY, Vellore- Tamilnadu, India; ${ }^{2}$ Christian Medical College, NEPHROLOGY, Vellore- Tamilnadu, India

\section{R. SLEDAl vs VCAM levels}

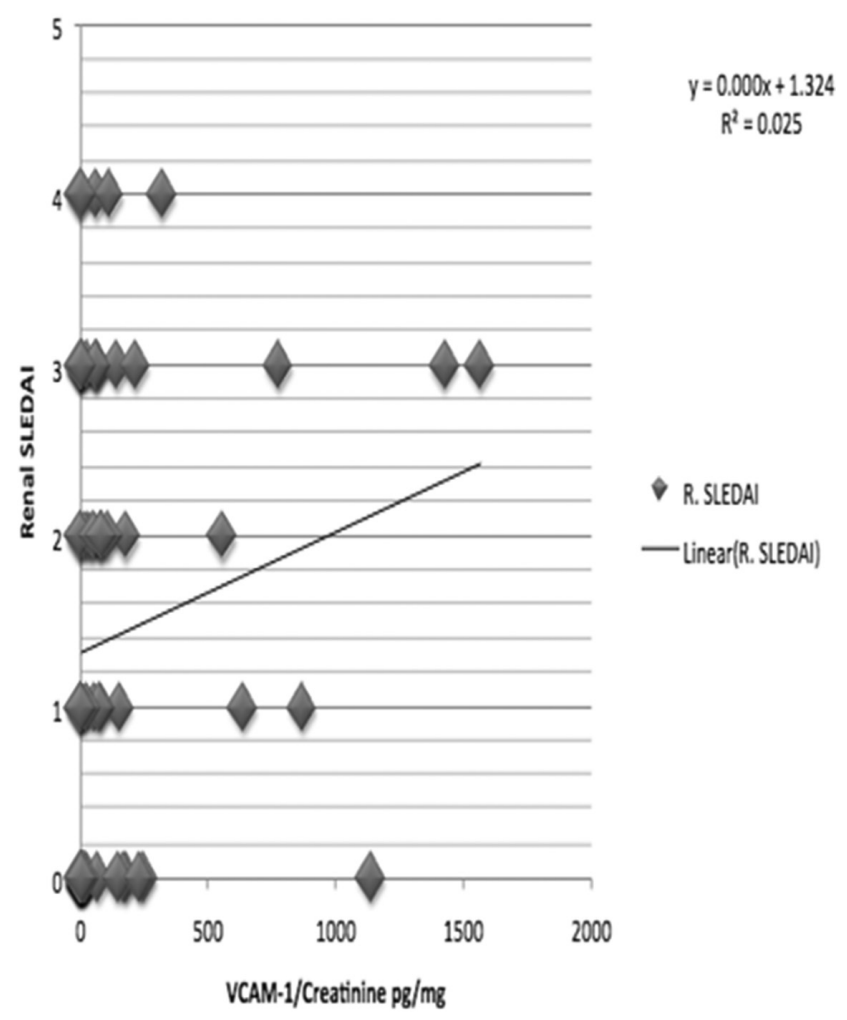

Abstract 303 Figure 1

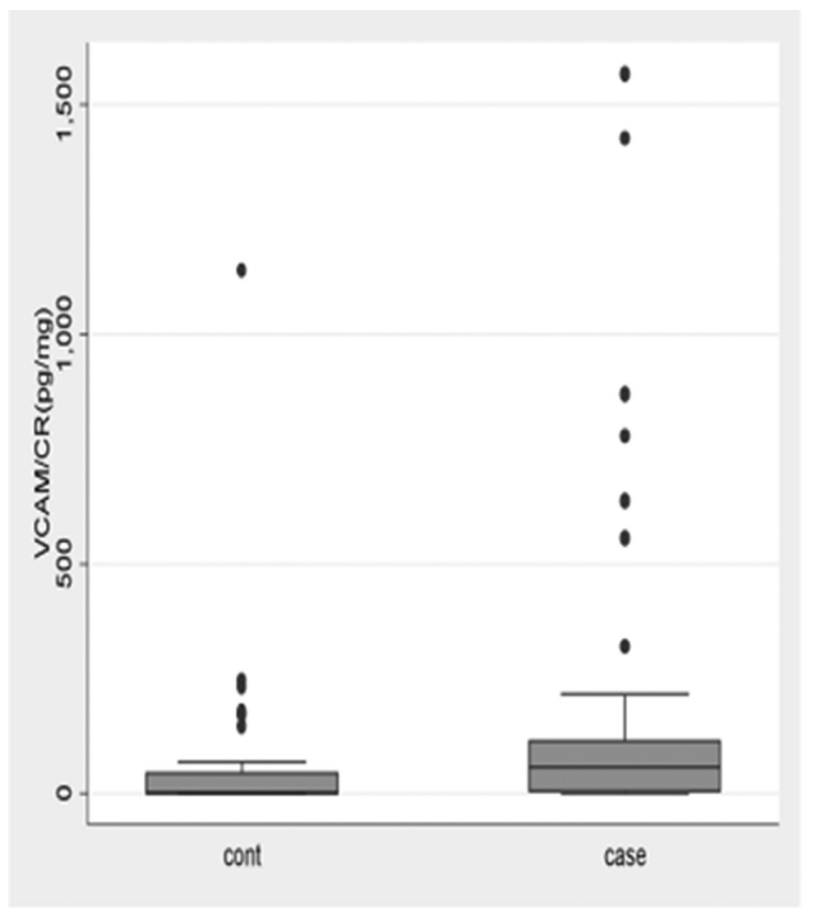

Scatter plot showing VCAM values in cases (with active nephritis)

\section{And controls (without nephritis)}

Abstract 303 Figure 2

Background and aims Currently we do not have a biomarker that can closely reflect the renal disease activity. So the aim of this study is to study the utility of urinary VCAM 1(Vascular cell adhesion molecule 1) in lupus nephritis.

Methods It was a diagnostic case control study. The patients presenting to Rheumatology outpatient department were recruited. Patients were divided into 2 groups, SLE without active nephritis and SLE with active nephritis based on the renal SLEDAI. Urinary VCAM1 was tested in all patients using an early morning spot urine sample using ELISA. Renal biopsy was done in patients with active nephritis. VCAM1 levels were compared with the renal SLEDAI, renal biopsy disease activity (ISNRPS) and standard of care markers. The results were analysd using SPSS software version 16.The validity and predictive value statistics was presented with 95 percent confidence interval.

Results Urinary VCAM 1 levels had significant correlation $(p=0.01)$ with disease activity based on renal SLEDAI. However, the correlation between the biopsy findings and VCAM levels was not statistically significant. Class 4 and 5 lupus nephritis had higher VCAM level than the lower classes. A positive correlation $(r=0.38)$ was found between VCAM 1 and double stranded DNA. There was a negative correlation between C3 value and VCAM $(\mathrm{r}=-0.19)$. The sensitivity and specificity of urinary VCAM 1 is $65.22 \%$ and $75 \%$ respectively. The cut off value of VCAM is $23.8 \mathrm{pg} / \mathrm{mg}$ of creatinine.

Conclusions Urinary VCAM 1 may not independently, but combined with other markers may be a promising biomarker for disease activity in lupus nephritis. 


\section{VCAM LEVELS IN VARIOUSCLASSES}

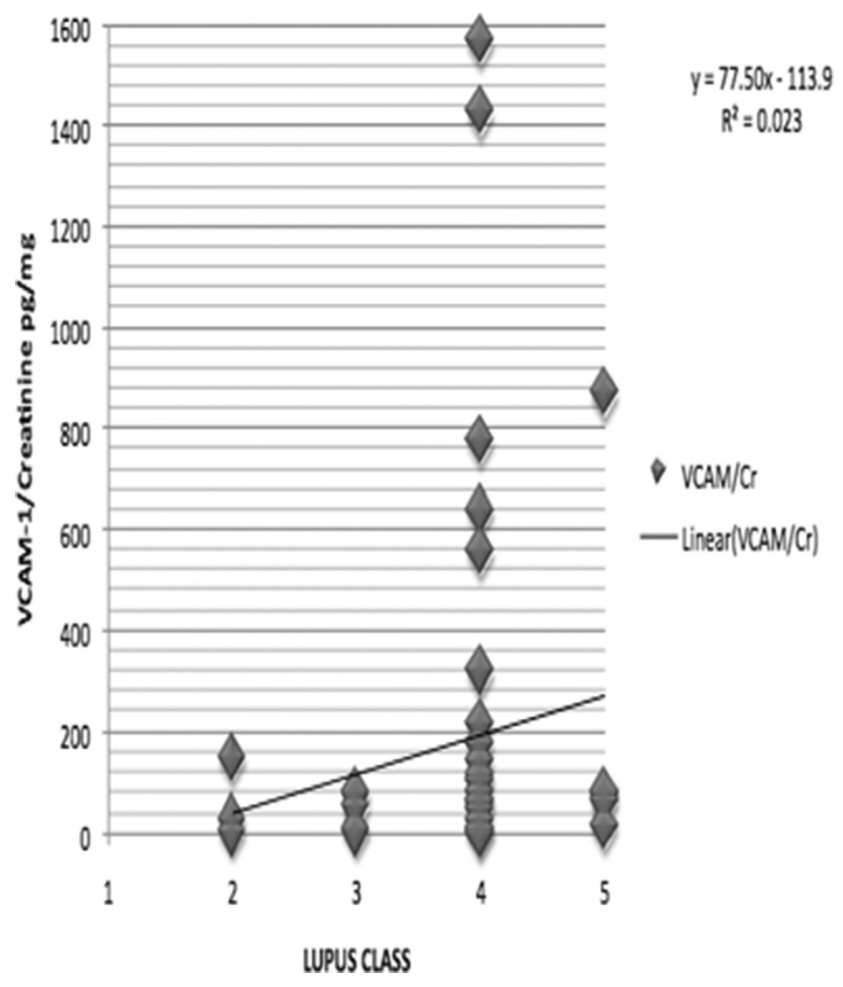

Abstract 303 Figure 3

\section{TNF-A PROMOTER POLYMORPHISMS (G-238A AND G- 308A) ARE ASSOCIATED WITH SUSCEPTIBILITY TO SYSTEMIC LUPUS ERYTHEMATOSUS: A STUDY IN P. FALCIPARUM ENDEMIC AREA}

${ }^{1}$ AK Panda*, ${ }^{1} \mathrm{H}$ MAHATO, ${ }^{2} \mathrm{R}$ Tripathy, ${ }^{3}$ BK Das. ${ }^{1}$ Central University of Jharkhand, Centre for Life Sciences, Ranchi, India; ${ }^{2}$ SCB Medical College, Department of Biochemistry, cuttack, India; ${ }^{3}$ SCB Medical College, Department of Medicine, cuttack, India

\subsection{6/lupus-2017-000215.304}

Background and aims Tumour necrosis factor- $\alpha$ (TNF- $\alpha$ ) is a proinflammatory cytokine associated with $P$. falciparum malaria and autoimmune disorders. Elevated plasma TNF-a has been linked to $P$. falciparum malarial severity and mortality. Higher levels of TNF- $\alpha$ has also been reported in systemic lupus erythematosus (SLE). Two functional common polymorphisms (G-238A and G-308A) at promoter region of TNF- $\alpha$ gene have been linked to SLE susceptibility in different population. In the present report, we conducted a case control study to investigate association of TNF- $\alpha$ (G-238A and G-308A) polymorphisms with susceptibility/resistance to SLE development in a P. falciparum malaria endemic cohort.

Methods A total of 204 female SLE patients and 224 age and sex matched healthy controls were enrolled in the study. TNF- $\alpha$ polymorphisms (G-238A and G-308A) were typed by polymerase chain reaction and restriction length polymorphism (PCR-RFLP). Plasma level of TNF-a was quantified by enzyme linked immunosorbent assay.
Results The prevalence of heterozygous mutants and minor alleles of TNF- $\alpha$ (G-238A and G-308A) polymorphisms were significantly higher in SLE patients compared to healthy controls. Furthermore, heterozygous (GA) and minor allele (A) of TNF- $\alpha$ (G-238A) polymorphism were associated with susceptibility to lupus nephritis. SLE patients displayed higher levels of plasma TNF- $\alpha$ compared to healthy controls. TNF- $\alpha$ (G$238 \mathrm{~A}$ and G-308A) variants were associated with higher plasma TNF- $\alpha$ in both SLE patients and healthy control.

Conclusions The results of the present study demonstrate that TNF- $\alpha$ (G-238A and G-308A) variants are associated with higher plasma TNF- $\alpha$ level and increased susceptibility to development of SLE in malarial endemic areas.

\section{ASSOCIATION OF C4A AND C4B GENOMIC COPY NUMBER VARIATIONS IN ADULT AND PAEDIATRIC SYSTEMIC LUPUS ERYTHEMATOSUS}

${ }^{1} \mathrm{P}$ Das*, RW Minz ${ }^{1},{ }^{1} \mathrm{~B}$ Saikia, ${ }^{2} \mathrm{~A}$ Sharma, ${ }^{3} \mathrm{~S}$ Singh. ${ }^{1}$ Postgraduate Institute of Medical Education and Research - Chandigarh, Immunopathology, Chandigarh, India; ${ }^{2}$ Postgraduate Institute of Medical Education and Research - Chandigarh, Internal Medicine, Chandigarh, India; ${ }^{3}$ Postgraduate Institute of Medical Education and Research Chandigarh, Advanced Paediatric Centre, Chandigarh, India

\subsection{6/lupus-2017-000215.305}

Background and aims C4 complement gene has been observed to be a susceptibility gene for SLE. Lower C4 gene (C4A and $\mathrm{C} 4 \mathrm{~B})$ copy number $(\mathrm{CN})$ is a risk factor for SLE, where as higher $\mathrm{C} 4 \mathrm{CN}$ is a protective factor. We investigated the association of $\mathrm{C} 4$ gene copy number variation in a north Indian cohort of SLE patients

Methods We recruited 112 aSLE and 52 pSLE patients with 115 healthy adult (CA) and 60 healthy paediatric (CP) controls and compared for $\mathrm{C} 4 \mathrm{~A}$ and $\mathrm{C} 4 \mathrm{~B} \mathrm{CN}$ by RT-PCR, serum C3, C4 by nephelometry and ANA autoantibodies by line blot assay

Results C4A low copy number was higher in pSLE $(\mathrm{OR}=1.82$, $\mathrm{p}=0.67)$ and aSLE $(\mathrm{OR}=1.51, \mathrm{p}=0.41)$ as compared to their respective controls, pSLE had higher C4A low copy number than the aSLE $(\mathrm{OR}=1.33, \mathrm{p}=0.58)$, though they were not statistically significant. $\mathrm{C} 4 \mathrm{~A}$ and $\mathrm{C} 4 \mathrm{~B} \mathrm{CN}$ negatively correlated with several ANA autoantibodies. The total $\mathrm{C} 4(\mathrm{C} 4 \mathrm{~A}+\mathrm{C} 4 \mathrm{~B})$ $\mathrm{CN}$ negatively correlated with Ro52 $(\mathrm{r}=-0.29, \mathrm{p}=0.03)$, dsDNA ( $\mathrm{r}=-0.32, \mathrm{p}=0.02)$, SSB $(\mathrm{r}=-0.33, \mathrm{p}=0.01)$, nucleosome $(r=-0.28, p=0.04)$ and histone $(r=-0.34, p=0.01)$ in pSLE and with nucleosome $(r=-0.20, p=0.03)$ in aSLE. The total $\mathrm{C} 4 \mathrm{CN}$ positively correlated with serum $\mathrm{C} 4$ level $(\mathrm{r}=0.26, \mathrm{p}=0.007)$ in both groups of patients

Conclusions We demonstrate that low copy numbers of complement genes correlate with the propensity for increased antibody secretion in both aSLE and pSLE. Thus, more productions of autoantibodies cause large number of immune complex formation with defective clearance process, due to low serum C4 level and low gene copy number 